\title{
The First Neptunium Dioxide Neutron Diffraction Experiment at HFIR
}

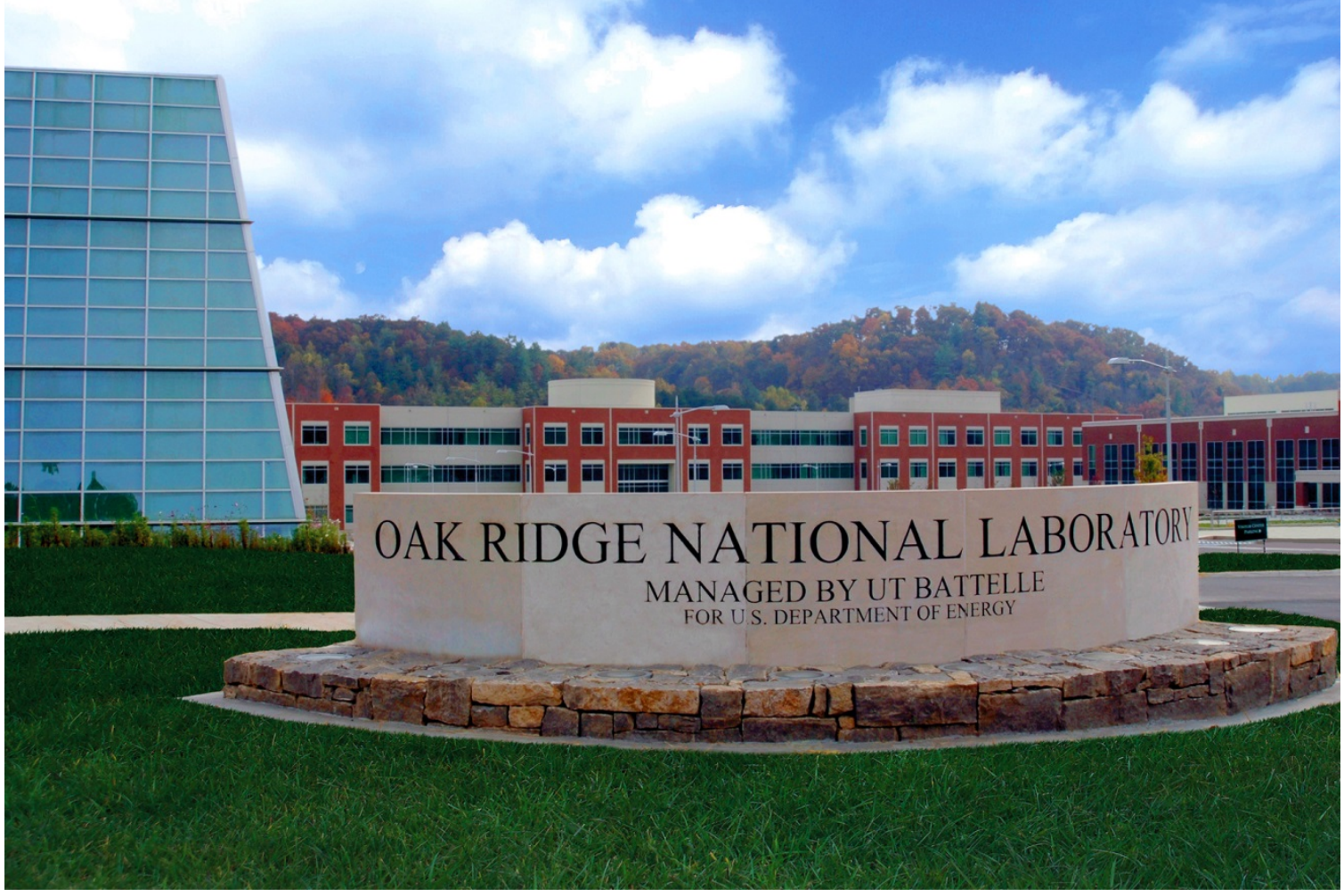

Luke R. Sadergaski

Samantha K. Cary

Kaara K. Patton

Matthias D. Frontzek

September 2021 


\title{
DOCUMENT AVAILABILITY
}

Reports produced after January 1, 1996, are generally available free via US Department of Energy (DOE) SciTech Connect.

Website www.osti.gov

Reports produced before January 1, 1996, may be purchased by members of the public from the following source:

\author{
National Technical Information Service \\ 5285 Port Royal Road \\ Springfield, VA 22161 \\ Telephone 703-605-6000 (1-800-553-6847) \\ TDD 703-487-4639 \\ Fax 703-605-6900 \\ E-mail info@ntis.gov \\ Website http://classic.ntis.gov/
}

Reports are available to DOE employees, DOE contractors, Energy Technology Data Exchange representatives, and International Nuclear Information System representatives from the following source:

Office of Scientific and Technical Information

PO Box 62

Oak Ridge, TN 37831

Telephone 865-576-8401

Fax 865-576-5728

E-mail reports@osti.gov

Website http://www.osti.gov/

This report was prepared as an account of work sponsored by an agency of the United States Government. Neither the United States Government nor any agency thereof, nor any of their employees, makes any warranty, express or implied, or assumes any legal liability or responsibility for the accuracy, completeness, or usefulness of any information, apparatus, product, or process disclosed, or represents that its use would not infringe privately owned rights. Reference herein to any specific commercial product, process, or service by trade name, trademark, manufacturer, or otherwise, does not necessarily constitute or imply its endorsement, recommendation, or favoring by the United States Government or any agency thereof. The views and opinions of authors expressed herein do not necessarily state or reflect those of the United States Government or any agency thereof. 
Radioisotope Science and Technology Division

\title{
THE FIRST NEPTUNIUM DIOXIDE NEUTRON DIFFRACTION EXPERIMENT AT HFIR
}

\author{
Luke R. Sadergaski \\ Samantha K. Cary \\ Kaara K. Patton \\ Matthias D. Frontzek
}

September 2021

Prepared by

OAK RIDGE NATIONAL LABORATORY

Oak Ridge, TN 37831-6283

managed by

UT-BATTELLE, LLC

for the

US DEPARTMENT OF ENERGY

under contract DE-AC05-00OR22725 



\section{CONTENTS}

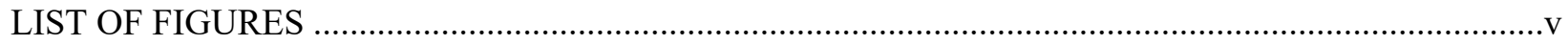

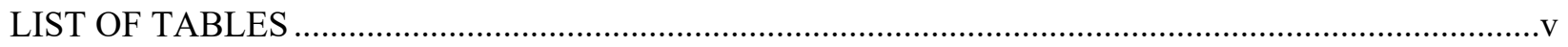

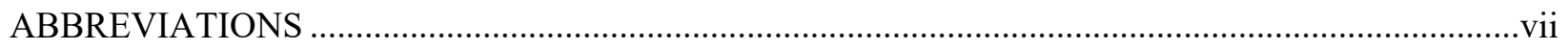

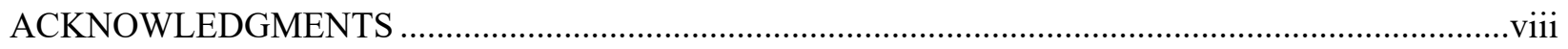

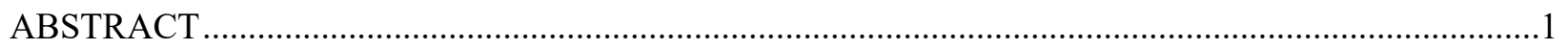

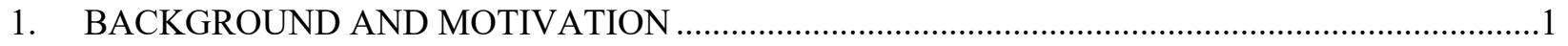

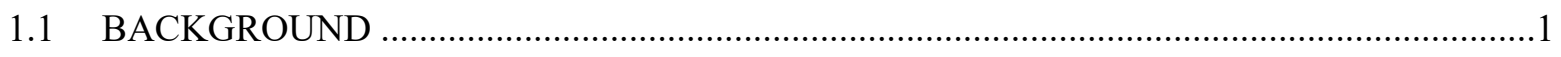

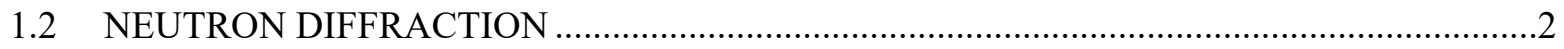

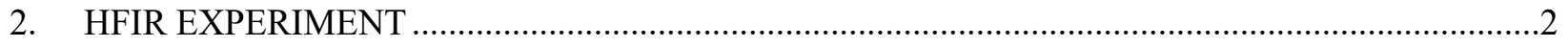

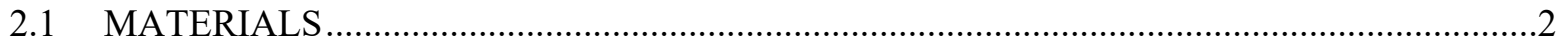

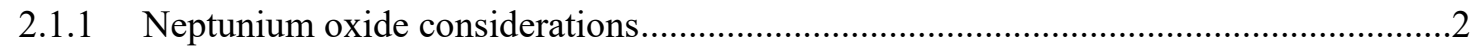

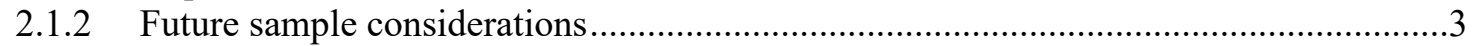

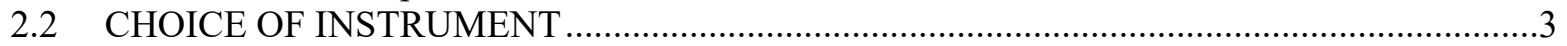

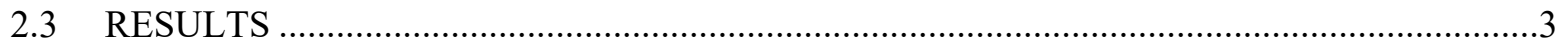

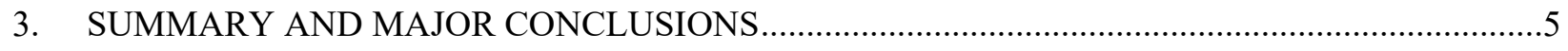

3.1 OUTCOMES AND FUTURE STUDIES AND APPLICATIONS …......................................

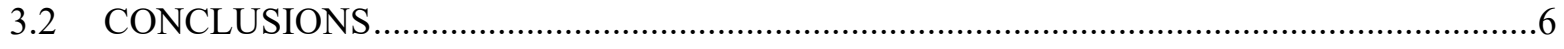

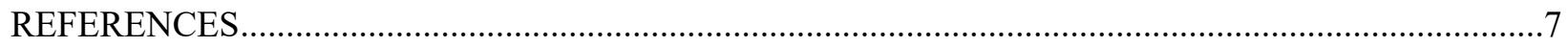





\section{LIST OF FIGURES}

Figure 2.1. $\mathrm{NpO}_{2}$ powder mounted inside a vanadium can on the wide-angle neutron diffraction

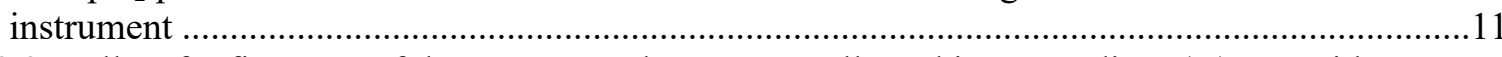

Figure 2.2. FullProf refinement of the $\mathrm{NpO}_{2}$ powder pattern collected in a vanadium (V) can with WAND $^{2}$.

Figure 2.3. Baseline corrected neutron diffraction pattern of $50 \mathrm{mg} \mathrm{NpO}$ powder.

\section{LIST OF TABLES}

Table 2.1. Neutron diffraction 2-theta peak positions. .12 



\section{ABBREVIATIONS}

HFIR High Flux Isotope Reactor

MDD modified direct denitration

NMC\&A nuclear material control and accounting

ORNL Oak Ridge National Laboratory

REDC Radiochemical Engineering Development Center

WAND $^{2} \quad$ wide angle neutron diffractometer

LDRD Laboratory Directed Research \& Development 


\section{ACKNOWLEDGMENTS}

Funding for this program was provided by NASA's Science Mission Directorate and administered by the US Department of Energy, Office of Nuclear Energy, under contract DEAC05-00OR22725. This work used resources at the High Flux Isotope Reactor, a Department of Energy Office of Science User Facility operated by Oak Ridge National Laboratory. 


\begin{abstract}
Here we present the first neutron diffraction experiment of a $50 \mathrm{mg}$ sample of neptunium(IV) dioxide $\left(\mathrm{NpO}_{2}\right)$ powder at the High Flux Isotope Reactor (HFIR) using the wide-angle neutron diffractometer $\left(\mathrm{WAND}^{2}\right) \mathrm{HB}-2 \mathrm{C}$. We also provide a brief literature survey to pinpoint gaps in the crystal, electronic, and magnetic structure of $\mathrm{NpO}_{2}$ to determine the optimum experiment to be pursued in the next HFIR user proposal cycle. Characterizing actinide materials with neutron diffraction, inelastic scattering, neutron imaging, polarized neutron studies, and small-angle neutron scattering techniques will increase our understanding of $5 f$ electron behavior and elucidate atomic and magnetic structural properties. This strategy will help fill gaps in the literature and provide theoretical physicists with the data needed to build physical and chemical models to guide and validate computational methods. These methods may be used for predicting structural and chemical features of actinide-based materials. This proof-of-principle effort begins to uncover how to advance actinide science and technology at Oak Ridge National Laboratory (ORNL) using neutron capabilities. This effort has already sparked collaborative discussions between researchers outside the Radioisotope Science and Technology Division, including theoretical physicists from the Nuclear Nonproliferation Division and beamline scientists in the Neutron Scattering Division. We intend to continue pursuing neutron experiments and develop a scientific strategy focused on studying transuranium elements (e.g., $\mathrm{Np}, \mathrm{Pu}, \mathrm{Am}$, and $\mathrm{Cm}$ ) using the advanced neutron capabilities at ORNL.
\end{abstract}

\title{
1. BACKGROUND AND MOTIVATION
}

\subsection{BACKGROUND}

Neptunium ( $\mathrm{Np}$ ) is the first transuranium element in the periodic table and characterizing fundamental $\mathrm{Np}$ properties is needed to systematically describe the actinide series. Neptunium-237 is the isotope most suitable for laboratory handling, and a large inventory has been accumulated worldwide as a by-product of the neutron irradiation of uranium fuel. Neptunium-237 is an important precursor to the production of ${ }^{238} \mathrm{Pu}$, a heat source material used by NASA to power deep space missions.

The ${ }^{238} \mathrm{Pu}$ Supply Program at ORNL irradiates ${ }^{237} \mathrm{~Np}$ containing aluminum- $\mathrm{NpO}_{2}$ cermet pellets to produce ${ }^{238} \mathrm{Pu}$ as $\mathrm{PuO}_{2}$ for NASA. ${ }^{1}$ High energy alpha radiation from the decay of ${ }^{238} \mathrm{Pu}\left(\mathrm{t}_{1 / 2}=87.7\right.$ years) can be used as a heat source for thermoelectric generators to power deep space probes for NASA. Neptunium(IV) dioxide $\left(\mathrm{NpO}_{2}\right)$ is produced by converting neptunium nitrate into neptunium oxide using the modified direct denitration (MDD) process. The MDD process produces a mixture of $\mathrm{NpO}_{2}$ and $\mathrm{Np}_{2} \mathrm{O}_{5}$, so this step is followed by heat treatment near $1,100^{\circ} \mathrm{C}$ to form $\mathrm{NpO}_{2}$. The final MDD oxide product may depend on the initial neptunium concentration, ammonium nitrate concentration, batch size, heating temperature, and heating time. Characterizing the produced $\mathrm{NpO}_{2}$ is important for the program to provide checks and balances before reaching the end of pellet fabrication. X-ray and neutron diffraction are among the best analytical methods to investigate oxide structural and chemical properties.

Neptunium has qualitatively similar chemical properties to uranium and plutonium, its closest neighbors on the periodic table. Neptunium forms two stable oxides, $\mathrm{NpO}_{2}$ and $\mathrm{Np}_{2} \mathrm{O}_{5}$, which correspond to neptunium(IV) and neptunium(V) valence states, respectively. ${ }^{2}$ Numerous studies indicate that the structure of $\mathrm{NpO}_{2}$ crystalizes in the $\mathrm{Fm} \overline{3} \mathrm{~m}$ space group where $\mathrm{Np}^{4+}$ cations and $\mathrm{O}^{2-}$ anions occupy octahedral and tetrahedral sites, respectively. Binary $\mathrm{Np}-\mathrm{O}$ compounds are dissimilar to $\mathrm{U}-\mathrm{O}$ and $\mathrm{Pu}-\mathrm{O}$ systems, which exhibit more structural varieties. ${ }^{3}$ No consensus has been reached on the existence of mixed valence $\mathrm{NpO}_{2+x}$ phases. However, a recent Extended X-ray Absorption Fine Structure study characterized several samples with varying numbers of oxygen atoms. ${ }^{4}$ Additional studies are needed to corroborate these findings. The state-of-the-art neutron capabilities at HFIR can be leveraged to generate 
new insights into the chemical and magnetic properties of neptunium including the stability of oxidation states, coordination preferences, chemical bonding, and magnetic ground state..$^{5-12}$

\subsection{NEUTRON DIFFRACTION}

Neutron diffraction data are needed to characterize atomic and magnetic structure of materials, including the actinide elements. It is also useful when characterizing atomic numbers that are far apart (e.g., neptunium and hydrogen) and distinguishing between isotopes of the same element. One of the most intriguing applications is magnetic scattering. Neutrons carry a magnetic moment and interact with magnetic moments materials to reveal the microscopic magnetic structure. Different types of magnetism include paramagnetic (PM), diamagnetic (DM), ferromagnetic (FM), antiferromagnetic (AFM), and ferrimagnetic (FI) behavior. The magnetic ground state of $\mathrm{UO}_{2}$ is well established by numerous authors and corroborated by multiple techniques including heat capacity, magnetic susceptibility, and neutron diffraction. ${ }^{7}$ Despite this, the magnetic ground state of $\mathrm{NpO}_{2}$ is complex and poorly understood because of several experimental inconsistencies. ${ }^{8}$ Magnetic susceptibility and specific heat capacity measurements indicate that a first-order PM-AFM phase transition occurs at low temperatures near $25.4 \mathrm{~K} .{ }^{9,10}$ Other techniques including resonant $\mathrm{X}$-ray scattering $(10 \mathrm{~K}<\mathrm{T}<17 \mathrm{~K})$ and ${ }^{17} \mathrm{O}$ nuclear magnetic resonance measurements $(\mathrm{T}=17 \mathrm{~K})$ indicate longitudinal 3k AFM behavior. ${ }^{11}$ However, other methods including low temperature Mossbauer $(\mathrm{T}=1.5 \mathrm{~K})$ and neutron diffraction $(12 \mathrm{~K}<\mathrm{T}<30 \mathrm{~K})$ have not identified a magnetic moment. ${ }^{8}$ Distortion of $\mathrm{O}^{2-}$ ions may result in $\mathrm{Pa} \overline{3}$ symmetry and could account for transverse $3 \mathrm{k}$ AFM behavior, but this has not been confirmed experimentally. The neutron diffraction capabilities at ORNL could be used to revisit these measurements to provide new data to the scientific community and answer important questions for actinide science.

Initial experimental ideas will be deliberated primarily with scientists at HFIR because of anticipated radiological constraints at the Spallation Neutron Source. Researchers from Radioisotope and Science Technology Division (RSTD) are collaborating with Matthias Frontzek and Stuart Calder, two neutron diffraction scientists at HFIR. They encouraged the submission of a proposal for a proof-of-principle experiment to characterize $\mathrm{NpO}_{2}$ powder using the wide-angle neutron diffraction instrument. Most neutron scattering experiments require near gram quantities of material. The material limits pose a challenge for actinides because of their scarcity, radiotoxicity, and material limits. Preliminary experiments were necessary to determine the quantity of material needed to obtain an adequate signal. The wide-angle neutron diffraction instrument $\left(\mathrm{WAND}^{2}\right)$ at HFIR is particularly suited for this task because it is designed to examine powders and single crystals.

\section{HFIR EXPERIMENT}

\subsection{MATERIALS}

\subsubsection{Neptunium oxide considerations}

All chemicals were commercially obtained (ACS grade). Neptunium dioxide $\left(\mathrm{NpO}_{2}\right)$ was synthesized at ORNL using the MDD process followed by a heat treatment at $1,000{ }^{\circ} \mathrm{C}$. Neptunium-237 is an alphaemitting radionuclide with a half-life of $2.144 \times 10^{6}$ years and should be handled with care. The oxide sample was synthesized 1 year before this experiment. Because of its age, it is now considered to be in secular equilibrium with ${ }^{233} \mathrm{~Pa}$, which has a half-life of 26.975 days. The activity of the parent the daughter is $0.031 \mathrm{mCi}$ each. The sample mass was $50 \mathrm{mg}$ of $\mathrm{NpO}_{2}$ powder, which equates to $44 \mathrm{mg}$ of ${ }^{237} \mathrm{~Np}$. This quantity is not an accountable item from a nuclear material control and accounting (NMC\&A) perspective. The powder was placed in a vanadium can and sealed with an indium gasket. Before placing the vanadium can into the hood, it was parafilmed, leaving the top of the can open for loading. A funnel was made with weigh paper to help guide the sample cleanly into the can. This method allowed us to keep 
the vanadium can clean with minimal effort. A radiological control technician (RCT) observed the operation and performed a smear test to ensure that the can was not contaminated before transfer to HFIR. A Radiochemical Engineering Development Center (REDC) staff member walked the yellow-tagged sample to HFIR and remained with the sample during the analysis.

\subsubsection{Future sample considerations}

Any sample containing ${ }^{237} \mathrm{~Np}$ must receive authorization before transfer between REDC and HFIR. This includes a sample transfer request and screening. Special considerations would not be necessary if a nonreportable quantity of ${ }^{237} \mathrm{~Np}$ was analyzed overnight at HFIR. If future experiments require greater than $50 \mathrm{mg}$ of ${ }^{237} \mathrm{~Np}$, the item would be accountable by NMC\&A, and more rigorous measures would have to be taken to ensure the sample is always secured. We expect that mixed oxide phases containing $\mathrm{NpO}_{2} / \mathrm{Np}_{2} \mathrm{O}_{5}$ would be quantifiable using a total of approximately $50 \mathrm{mg}$ of $\mathrm{Np}$. This could provide valuable characterization data for the MDD product. A larger mass of $\mathrm{Np}$ may be necessary for neutron imaging experiments to study mixed $\mathrm{NpO}_{2}$-aluminum cermet pellets for the ${ }^{238} \mathrm{Pu}$ Supply Program. The pellets comprise $\sim 0.6 \mathrm{~g}$ of $\mathrm{NpO}_{2}$. REDC material balance area representatives (MBARS) are confident that this could be accomplished, but it will ultimately be left up to local inventory management at HFIR. Onus is mostly on the receiver. This may include setting up a temporary nuclear materials storage area with an NMC\&A approved lock to secure the sample chamber. It would not be necessary to use a tamperindicating device because they are reserved for on-site transfers of $\geq 50 \mathrm{~g}$ of special nuclear material.

\subsection{CHOICE OF INSTRUMENT}

We obtained beam time using the WAND ${ }^{2}$ at HFIR. This instrument is ideal for the analysis we propose because it is optimal for relatively small powder sample sizes. The neutron powder diffractogram was collected under ambient conditions using the wide-angle neutron diffractometer (WAND ${ }^{2}$ ) (see Figure 2.1).

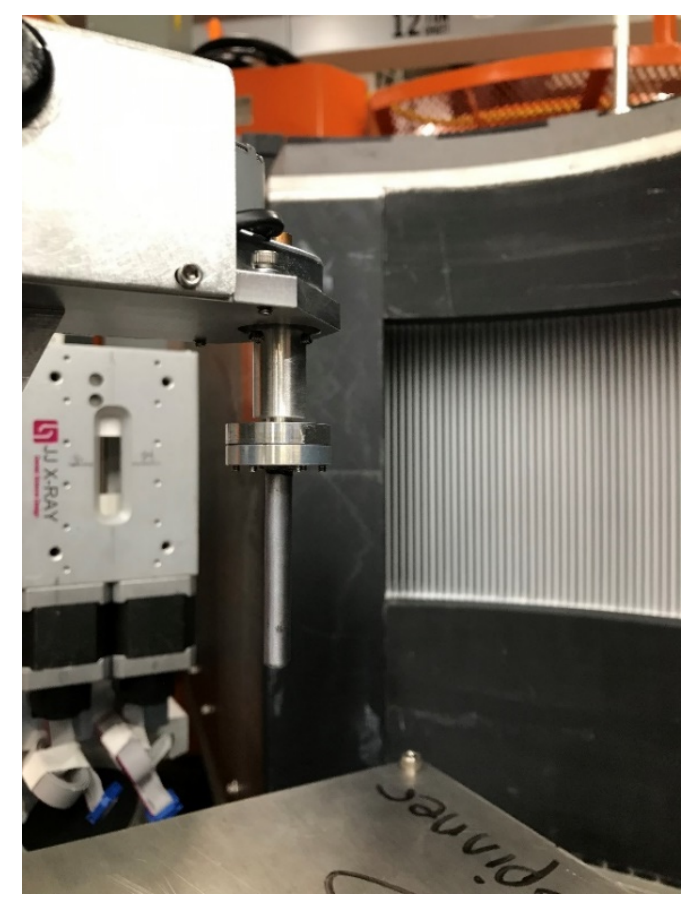

Figure 2.1. $\mathrm{NpO}_{2}$ powder mounted inside a vanadium can on the $\mathrm{WAND}^{2}$ instrument. 


\subsection{RESULTS}

The resulting neutron diffraction pattern was analyzed using FullProf, a standard Rietveld refinement program used by beamline scientists to refine the structure (see Figure 2.2). There was low residual difference between the experimental data and the refined pattern.

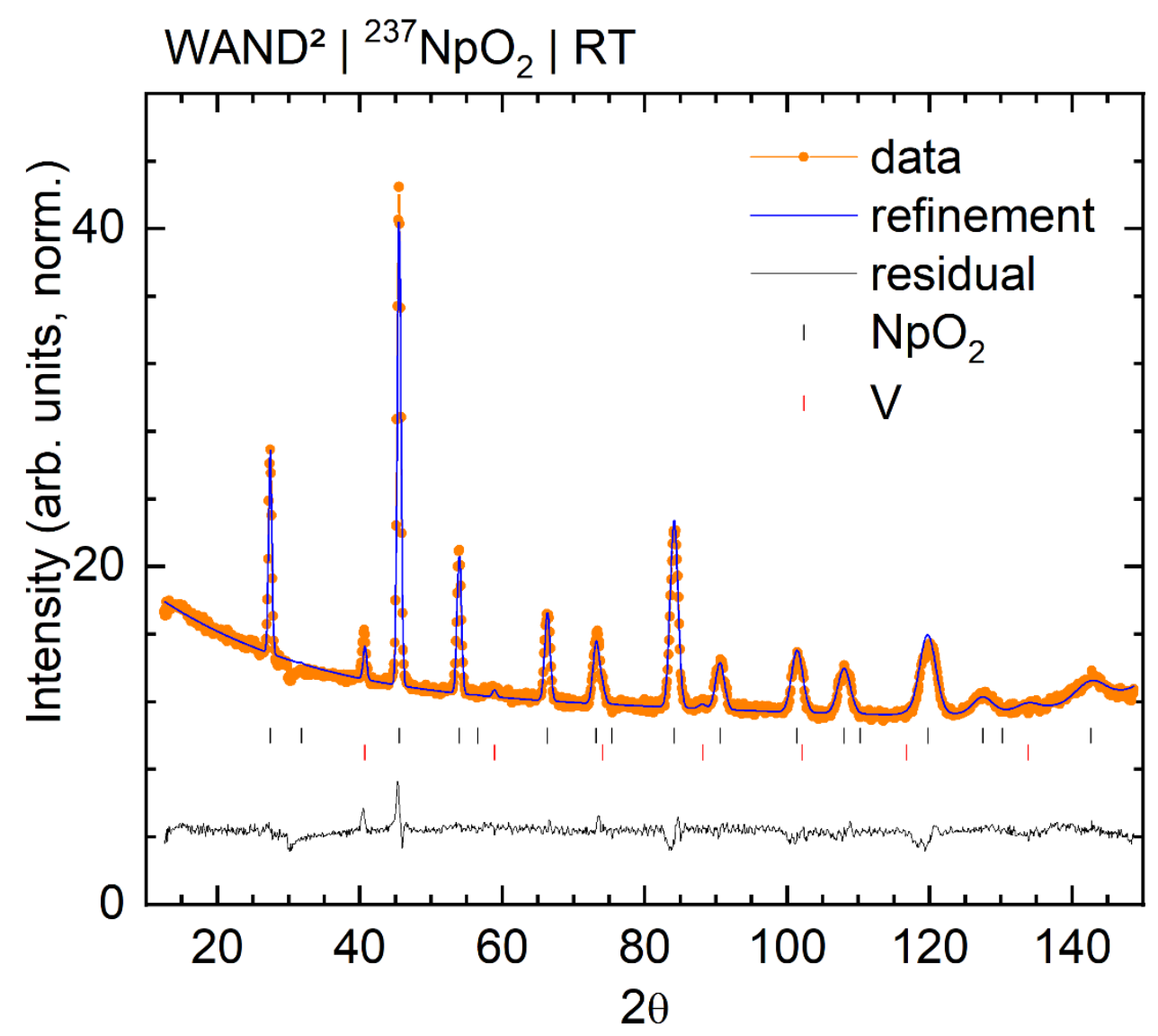

Figure 2.2. FullProf refinement of the $\mathrm{NpO}_{2}$ powder pattern collected in a vanadium (V) can with WAND 2 .

An acceptable neutron signal was acquired using just $50 \mathrm{mg}$ of $\mathrm{NpO}_{2}$ (see Figure 2.3). Ten Bragg peaks for $\mathrm{NpO}_{2}$ were identified, and each $2 \theta$ value listed in Table 1 agreed with X-ray diffraction data. ${ }^{4} \mathrm{An}$ additional Bragg peak was found at $40.62 \theta$, which corresponds to vanadium metal sample holder. 


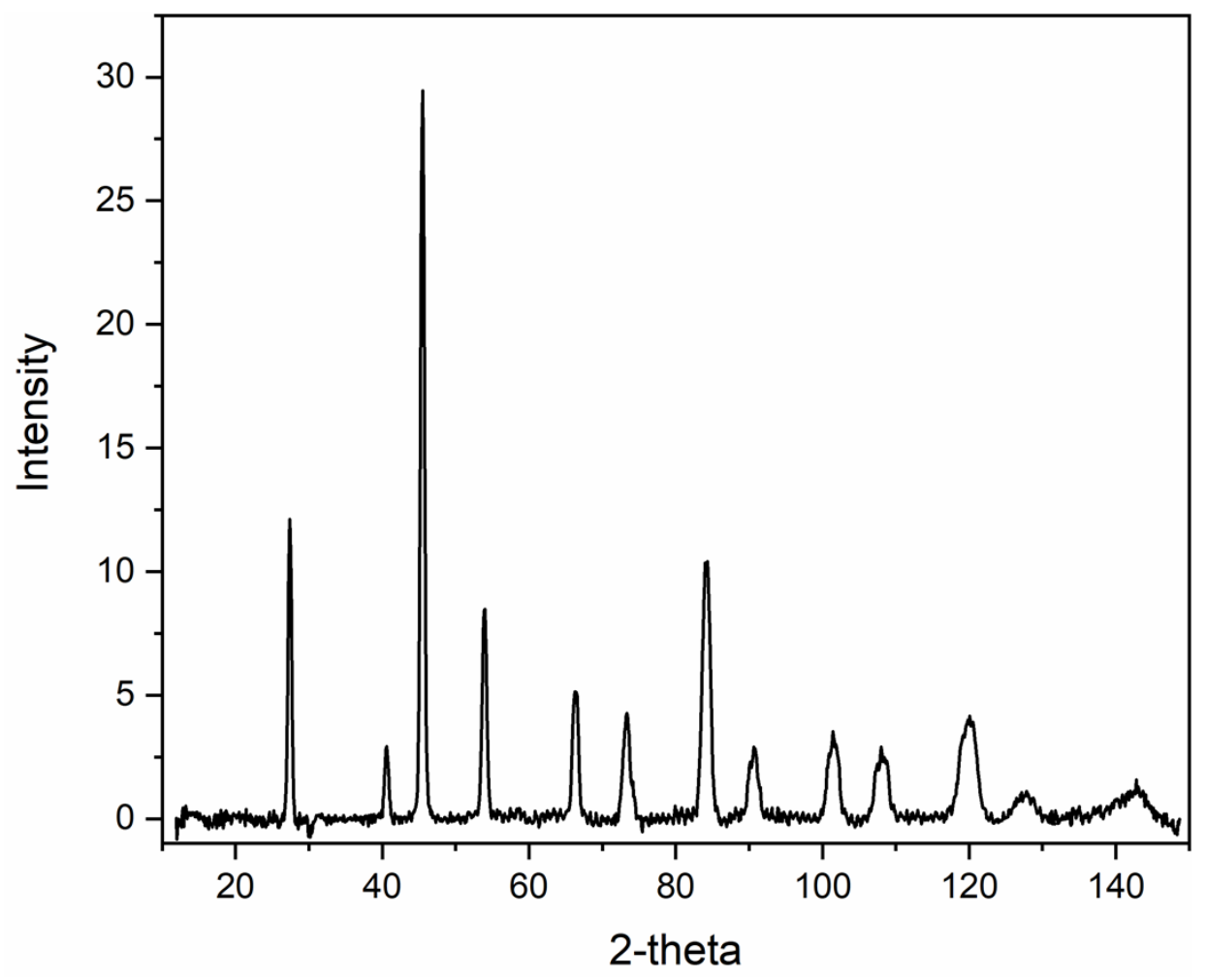

Figure 2.3. Baseline corrected neutron diffraction pattern of $50 \mathrm{mg} \mathrm{NpO}_{2}$ powder.

Table 2.1. Neutron diffraction 2-theta peak positions.

\begin{tabular}{cc}
\hline ID & $\mathbf{2} \boldsymbol{\theta}$ \\
\hline 1 & 27.5 \\
2 & 45.2 \\
3 & 54.0 \\
4 & 66.4 \\
5 & 73.3 \\
6 & 84.3 \\
7 & 90.7 \\
8 & 101.4 \\
9 & 108.3 \\
10 & 119.9 \\
\hline
\end{tabular}




\section{SUMMARY AND MAJOR CONCLUSIONS}

\subsection{OUTCOMES AND FUTURE STUDIES AND APPLICATIONS}

Significant outcomes of this work are at least threefold: this effort (1) established partnerships with experts from multiple directorates, (2) characterized a specimen comprised primarily of a transuranium element, (3) demonstrated the capacity from a technical and regulatory basis to characterize sub accountable quantities of transuranium materials, and (4) activated a steppingstone toward studying heavier transuranium elements at HFIR. Although uranium compounds are analyzed on a regular basis, tranuranium compounds are rarely characterized using ORNL neutron diffraction techniques. This is due to multiple constraints including regulatory, safety, and sample size. Typically, a relatively large sample size (approximately $\geq 0.5 \mathrm{~g}$ ) is necessary for a neutron diffraction experiment. This work presents a means by which relatively small quantities of transuranium compounds can be characterized by neutron diffraction. This quantity is manageable from radiological, accountable, and scarcity perspectives.

We plan to submit a full HFIR beamline user proposal to interrogate magnetic properties of $\mathrm{NpO}_{2}$ at low temperature. This will include using either a closed cycle refrigerator or a closed loop cryogenic system (Heliox-ACV), which can achieve $4 \mathrm{~K}$ and $300 \mathrm{mK}$ temperatures, respectively. The closed cycle refrigerator requires an 8 hour cool down time, and the CLS requires a full 24 hours. The sample can must be filled with helium, which may be accomplished using a glovebox at HFIR facilities. The magnetic field at $\mathrm{WAND}^{2}$ will initially start at $0 \mathrm{~T}$ and approach the maximum field of $6 \mathrm{~T}$, if necessary.

The magnetic ground state of actinide dioxides $\left(\mathrm{AnO}_{2}\right)$ must be rigorously defined to design consistent computational models. Low temperature characterization to determine magnetic ground state is complicated for several reasons, including radiotoxicity, nucleonic radioactive decay, and inhomogeneous samples. Before this experiment, a fresh batch of $\mathrm{NpO}_{2}$ will be synthesized with minimal protactinium. The experiment may include subsequent measurements to study how the ingrowth of protactinium influences magnetic susceptibility.

This study is intended to ignite a science strategy plan to fill knowledge gaps in the literature. It will provide theoretical physicists with the data needed to build physical and chemical models required to guide and validate computational methods for predicting structural and chemical features of actinidebased materials. Pending successful results from this study, we plan to compose new proposals to acquire dynamic data sets including temperature, pressure, and magnetic field effects to study lattice expansion parameters, phase or topological transitions, and magnetic properties. This may include developing a scientific strategy focused on studying transuranium elements (e.g., $\mathrm{Np}, \mathrm{Pu}, \mathrm{Am}, \mathrm{Cm}$, and beyond) using the advanced neutron capabilities at ORNL. Characterizing transuranium materials with neutron diffraction, inelastic scattering, imaging, polarized neutron studies, and small-angle neutron scattering techniques will increase our understanding of $5 f$ electron behavior and elucidate atomic and magnetic structural properties.

\subsection{CONCLUSIONS}

In June 2021, a $50 \mathrm{mg}$ sample of $\mathrm{NpO}_{2}$ powder was successfully characterized using the WAND ${ }^{2}$ at HFIR. This proof-of-concept measurement demonstrates the ability to characterize subaccountable quantities of neptunium-containing compounds at HFIR, and it opens the door for leveraging neutron diffraction capabilities at ORNL to generate new insights into chemical and magnetic properties of transuranium compounds. It also creates the opportunity to collaborate with modeling/simulation experts from the Nuclear Nonproliferation Division and provide them with data that are essential to validate/inform predictive models. 
Ultimately, this work was a major feat for the entire scientific community and began connecting the gap between actinide and neutron sciences at ORNL. Because of this successful experiment, we are submitting a full user proposal for a more detailed experiment at HFIR, which could take place as early as December 2021. Pending results from this effort, we plan to write a LDRD SEED proposal to support the analysis of numerous data sets including temperature, pressure, and magnetic field effects to study lattice expansion parameters, phase or topological transitions, and magnetic properties. Future work may also include neutron imaging of mixed aluminum- $\mathrm{NpO}_{2}$ cermet pellets, neutron diffraction of various neptunium crystal structures, and the analysis of $\mathrm{PuO}_{2}$ and other plutonium structures prior before characterizing transplutonium compounds.

This effort would support radioisotope production program missions, cut across multiple directorates and support ORNL's actinide science strategy. Conversations with personnel who oversee safety and regulations at the neutron facilities is also continuing.

\section{REFERENCES}

[1] Sadergaski, L.; Myhre, K.; Delmau, L.; Benker, D.; DePaoli, D.; Wham, R. Spectroscopic and Multivariate Analysis Development in Support of the Plutonium-238 Supply Program. Nuclear and Emerging Technologies for Space, 2020.

[2] Forbes, T. Z.; Burns, P. C.; Skanthakumar, S.; Soderholm. L. Synthesis, Structure, and Magnetism of $\mathrm{Np}_{2} \mathrm{O}_{5}$. J. Am. Chem. Soc. 2007, 129 (10), 2760-2761.

[3] Haschke, J. M.; Allen, T. H.; Morales, L. A. Reaction of Plutonium Dioxide with Water: Formation and Properties of $\mathrm{PuO}_{2+\mathrm{x}}$. Science 2000, 285-287.

[4] Tayal, A.; Conradson, S. D.; Baldinozzi, G.; Namdeo, S.; Roberts, K.; Allen, P. G.; Shuh, D. K. Identification of $\mathrm{NpO}_{2+\mathrm{x}}$ in the Binary Np-O System. J. Nucl. Mater. 2017, 490, 279-287.

[5] Amoretti, G.; Blaise, A.; Caciuffo, R.; Cola, D. D.; Fournier, J. M.; Hutchings, M. T.; Lander, G. H.; Osborn, R.; Severing, A.; Taylor, A. D. Neutron-Scattering Investigation of the Electronic Ground State of Neptunium Dioxide. J. Phys.: Condens. Matter 1992, 4, 3459.

[6] Heaton, L.; Mueller, M. H.; Williams, J. M. A Neutron Diffraction Determination of the Coherent Scattering Amplitude of $\mathrm{Np}$ and the Possible Antiferromagnetism of Neptunium Dioxide. J. Phys. Chem. Solids 1967, 28 (9), 1651-1654.

[7] Pegg, J. T.; Shields, A. E.; Storr, M. T.; Wills, A. S.; Scanlon, D. O.; Leeuw, N. H. Magnetic Structure of $\mathrm{UO}_{2}$ and $\mathrm{NpO}_{2}$ by First-Principles Methods. Phys. Chem. Chem. Phys. 2019, 21, 760.

[8] Caciuffo, T.; Lander, G. H.; Spirlet, J. C. A Search for Anharmonic Effects in $\mathrm{NpO}_{2}$ at Low Temperature by Neutron Diffraction. Solid State Commun. 1987, 64 (1), 149-152.

[9] Erdös, P.; Solt, G.; Zołnierek, G.; Blaise, A.; Fournier, J. M. Magnetic Susceptibility, and the Phase Transition of $\mathrm{NpO}_{2}$. Physica $B+C, \mathbf{1 9 8 0}, 102,164-170$.

[10] Westrum, E. F. Jr.; Hatcher, J. B.; Osborne, D. W. The Entropy and Low Temperature Heat Capacity of Neptunium Dioxide. J. Chem. Phys. 1953, 21, 419-413.

[11] Mannix, D.; Lander, G. H.; Rebizant, J.; Caciuffo, R.; Bernhoeft, N.; Lidstrom, E.; Vettier, C. Unusual Magnetism of $\mathrm{NpO}_{2}$ : A Study with Resonant X-ray Scattering. Phys. Rev. B: Condens. Matter Mater. Phys., 1999, 60 (22), 15187-15193.

[12] Westrum, E. F. Jr.; Osborne, D. W. The Heat Capacity of Thorium Dioxide from 10 to $305^{\circ} \mathrm{K}$. The Heat Capacity Anomalies in Uranium Dioxide and Neptunium Dioxide. J. Chem. Phys., 1953, 21, 1884 . 
